\title{
Identification of characteristic aroma compounds in raw and thermally processed African giant snail (Achatina fulica)
}

\author{
Ola Lasekan*, Megala Muniady, Mee Lin and Fatma Dabaj
}

\begin{abstract}
Background: Food flavor appreciation is one of the first signals along with food appearance and texture encountered by consumers during eating of food. Also, it is well known that flavor can strongly influence consumer's acceptability judgment. The increase in the consumption of snail meat across the world calls for the need to research into the aroma compounds responsible for the distinctive aroma notes of processed snail meat.

Results: The odorants responsible for the unique aroma notes in thermally processed giant African snail meats were evaluated by means of aroma extract dilution analysis (AEDA), gas chromatography-olfactometry (GC-O) and odor activity values (OAVs) respectively. Results revealed significant differences in the aroma profiles of the raw and thermally processed snail meats. Whilst the aroma profile of the raw snail meat was dominated with the floral-like $\beta$-ionone and $\beta$-iso-methyl ionone, sweaty/cheesy-like butanoic acid, and the mushroom-like 1-octen-3-one, the boiled and fried samples were dominated with the thermally generated odorants like 2-methylpyrazine, 2,5-dimethylpyrazine, 2-acetylthiazole and 2-acetylpyridine.

Conclusion: Finally, results have shown that sotolon, 2-acetyl-1-pyrroline, 2-furanmethanethiol, 2-methylbutanal, 1-octen-3-one, octanal, furanone, 2-methoxyphenol, 2-acetylpyridine, 2-acetylthiazole, and 2-methylpyrazine contributed to the overall aroma of the thermally processed snail meat.
\end{abstract}

Keywords: African giant snails, Aroma compounds, Thermal process, AEDA, OAVs

\section{Background}

The giant African snail (Achatina fulica Bowdich) belongs to the Achatinoidea family and its native to East Africa. However, it has been widely distributed to different parts of the world such as; China [1], Taiwan [2], India, West Indies and the United States [3]. The snail's habitat covers the dense tropical forest of West Africa, Pacific Islands, Southern and Eastern Asia, and the Caribbean [4]. Different breeds of land snails have been reported and the most common breeds in Africa are Achatina achatina, Achatina fulica, Achachatina marginata and Limocolaria species [5]. The giant African snail is considered as one of the worst invasive species, because of its impact on agricultural and horticultural crops [6].

\footnotetext{
*Correspondence: olaniny56@gmail.com Department of Food Technology, University Putra Malaysia, UPM, 43400 Serdang, Malaysia
}

In spite of its invasive activities, African giant snails have been reported to exhibit antimicrobial properties. For instance, snails produce mucin in abundance in their mucus secretion. The mucin also called slim contains a bactericidal glycoprotein known as 'achacin' [7]. Also, the use of snail mucin for wound healing has been reported [8]. The giant African snails are highly relished delicacy in some parts of Africa, Taiwan, and South Korea [9]. France is the world leading consumer of snails followed, in order by Italy, Spain and Germany [10]. The snails are excellent sources of nutrition, as they contain abundant levels of calcium, phosphorous, magnesium and protein [11]. In addition, the distinctive aroma of fried snails is very effective in enhancing the flavor of dishes.

Several studies have been reported on the volatile composition of edible freshwater mollusks such as clams [12], mussels, shrimp and squid [13]. Sekiwa et al. [12] 
identified 49 compounds in clams among which were; 2,5-dimethyl-4-hydroxy-3(2H)-furanone, 2-acetyl-2-thiazoline, 2-acetylthiazole and 3-methylthiopropanal. Whereas, Giogios et al. [13], reported high amounts of aldehydes, furans, and N-containing compounds (i.e. pyridine, pyrazines and pyrroline) in mussels. However, for the overall aroma of oysters, the main compounds were 3-cyclohexene-1-ethanol (Z)-1,5-octadien-3-ol, 2-octen1-ol, benzaldehyde and lilac aldehyde [14]. In another study, on the potent aroma compounds in dried scallops (Patinopecten yessoensis), Chung, Yung, Ma and Kin [15] found pentanal, 2-methylene-hexanal, 1,2-dichlorobenzene, 1-methoxy-4-(2-propenyl)-benzene, ethyl benzoate and $(Z)$-jasmone as some of the potent compounds. The effects of thermal processing and/or conservation treatments on volatile compounds generation in fish and fish products have also been documented. For example, while hexanal, 2-ethyl-1-hexanol, dimethylsulphide, 6-methyl-5-hepten-2-one, nonanal, 1-octen-3-one and $y$-butyrolactone were reported as the major volatile compounds in raw Mediterranean shrimps [16], the cooked shrimps produced appreciable amounts of 2-methylbutanal, 3-methylbutanal. 2,6-dimethylpyrazine, dimethylsufoxide, 1-dodecanol in addition to hexanal and dimethyl sulphide [16]. Li et al. [17] reported significant amounts of furans in fried grass fillet carp (Ctenopharyngodon idellus). The major compounds identified in the fried fillets were: 6-heptyltetrahydro-2H-pyran-2-one, 2,5-dimethyl4-hydroxy-3(2H)-furanone, 5-hydroxymethylfurfural, decanal, 3-methyl-1-butanol, 2-pentylfuran and 2,5-dimethyl-3-ethylpyrazine. Apart from the effect of thermal processing, conservation treatment such as salting has been known to influence volatile production. For instance, Conte et al. [18] reported that salted red mullet (Mullus surmuletus) exhibited high levels of hexanal, heptanal and (Z)-4-heptanal.

From a consumer perspective, the most appealing features of a processed snail meat are its flavor and nutrition. Food flavor appreciation is one of the first evaluation signals along with food appearance and texture encountered by consumers during eating [19].

However, to the best of our knowledge, there has been no report on the odorants responsible for the typical flavor of processed giant African snail. The aim of this study was to evaluate the potent aroma-active compounds in thermally processed giant African snail.

\section{Results and discussion}

\section{Odorants in raw snail meat}

The aroma-active compounds in raw and thermally processed African giant snail meat (A. fulica) were evaluated. The most aroma-active components identified in the raw snail meat are listed in Table 1 and Fig. 1 respectively. The application of aroma extract dilution analysis (AEDA) and gas chromatography olfactometry $(\mathrm{GC}-\mathrm{O})$ revealed 13 odor-active compounds with FD factors from 4 to 32 . Of this number, 8 odorants were obtained in the neutral basic fractions $(\mathrm{NBF})$, while 5 odorants were found in the acidic fraction (AF). The major odorants with flavor dilution $(\mathrm{FD} \geq 8)$ in the raw snail meat were 1-octen-3one, benzaldehyde, octanal, $\beta$-ionone and $\beta$-iso-methyl ionone. Odorant with the least FD of 2 was identified as 2,3-pentanedione. 2,3-Pentanedione, 1-octen-3-one, benzaldehyde and octanal have been widely reported in different species of mollusks such as shellfish [20], squid [21] and steamed mangrove crab [22]. However, $\beta$-iso-methyl ionone (Apo-carotenoid) to the best of our knowledge has not previously been detected or described in snail meat or any other mollusks.

\section{Odorants in boiled snail meat}

The aroma-active compounds in boiled African giant snail meat (A. fulica) were also evaluated by AEDA and GC-O respectively. A total of 19 odor-active compounds with flavor dilution (FD) factors ranging from 4 to 128 (Table 1) were detected. Of this number, 13 odorants were obtained in the neutral basic fractions (NBF), while the other 6 odorants were found in the acidic fractions (AF). The identified odorants produced an array of aroma nuances such as: buttery, malty, caramel-like, sweaty/ cheesy, popcorn-like, mushroom, seasoning, floral and roasty. Furthermore, results of the AEDA revealed that 2-acetylpyridine, 2-acetylthiazole, 1-octen-3-one, benzaldehyde, 2-methylbutanal, octanal and 3-hydroxy-4,5-dimethyl-2(5H)-furanone (sotolon) possessed the highest FD factors (Table 1). Lower FD factors were produced by acetoin, 2-methylpyrazine, 2,5-dimethylpyrazine, octadecanal, acetic acid, 2,3-pentanedione, butanoic acid, $\beta$-ionone, $\beta$-iso-methyl ionone, hexadecanoic acid, octadecanoic acid and 9,12-octadecadienoic acid $(Z, Z)$.

A comparative analysis of the aroma profiles of raw and boiled snail meats revealed a significant number of thermally generated odorants in the boiled snails. Some of the identified odorants were; 2-methylpyrazine, 2,5-dimethylpyrazine, 2-acetylthiazole and 2-acetylpyridine (Fig. 2). Whereas, the aroma profile of the raw snail meat was dominated by floral, faint fatty, mushroom and sweaty/cheesy notes, the boiled snail meat elicited malty, popcorn-like, seasoning and mushroom nuances (Fig. 3). While the aroma notes developed in the boiled snail meat strongly increased in the fried snail samples, the faint fatty and mushroom notes decreased significantly. In order to elucidate the reasons behind this observation, 
Table 1 Most aroma-active components (FD $\geq 4)$ in raw and boiled giant snail meat (A. fulica)

\begin{tabular}{|c|c|c|c|c|c|c|c|}
\hline No & Compound $^{a}$ & Odour note & Fraction $^{\mathbf{b}}$ & DB5 & FFAP & FD boiled & FD raw \\
\hline 1 & Acetoin & Buttery & NBF & nd & 1275 & 4 & 4 \\
\hline 2 & Acetic acid & Vinegar-like & $\mathrm{AF}$ & 635 & 1450 & 4 & 4 \\
\hline 3 & 2-Methylbutanal & Malty & NBF & 663 & 912 & 16 & nd \\
\hline 4 & 2,3-Pentanedione & Caramel & NBF & 696 & 1054 & 4 & 2 \\
\hline 5 & Butanoic acid & Sweaty, cheesy & $\mathrm{AF}$ & 835 & 1619 & 4 & 4 \\
\hline 6 & 2-Methylpyrazine & Popcorn & NBF & 820 & nd & 8 & nd \\
\hline 7 & 2,5-Dimethylpyrazine & Nutty, roasty & NBF & 906 & nd & 8 & nd \\
\hline 8 & Benzaldehyde & Almond-like & NBF & 963 & 1524 & 16 & 8 \\
\hline 9 & 1-Octen-3-one & Mushroom & NBF & 977 & 1295 & 32 & 32 \\
\hline 10 & Octanal & Citrus & NBF & 1006 & 1276 & 16 & 8 \\
\hline 11 & 2-Acetylthiazole & Roasty, earthy & NBF & 1020 & 1624 & 64 & nd \\
\hline 12 & 2-Acetylpyridine & Popcorn & NBF & 1031 & 1551 & 128 & nd \\
\hline 13 & 3-Hydroxy-4,5-dimethyl-2(5H) furanone (Sotolon) & Seasoning & AF & 1107 & 2200 & 16 & nd \\
\hline 14 & $\beta$-ionone & Floral & NBF & 1457 & 1959 & 4 & 8 \\
\hline 15 & $\beta$-iso-methyl ionone & Floral & NBF & 1534 & nd & 4 & 8 \\
\hline 16 & Octadecanal & Fatty & NBF & 1818 & 2179 & 8 & 4 \\
\hline 17 & Hexadecanoic acid & Waxy & AF & 1984 & 2940 & 4 & 4 \\
\hline 18 & Octadecanoic acid & Mild fatty & $\mathrm{AF}$ & 2178 & nd & 4 & 4 \\
\hline 19 & 9,12-Octadecadienoic acid $(Z, Z)$ & Faint fatty & AF & 2183 & nd & 4 & 4 \\
\hline
\end{tabular}

$A F$ acidic fraction, NBF neutral and basic fraction, FD flavour dilution

a Compounds were identified by comparing their retention indices on DB- 5 and FFAP columns, mass spectra, and their aroma impressions were compared with the respective reference compounds

b Fractions in which the odorants were detected by GC-O after fractionation

the fried snail meats were subjected to AEDA and $\mathrm{GC}-\mathrm{O}$ as earlier describe for the boiled snails.

\section{Odorants in fried snail meat}

A total of 22 aroma-active compounds were detected with FD factors between 4 and 256 (Table 2). Of this number, 16 odorants were obtained in the NBF while the rest were acidic fractions. The aroma-active compound with the highest FD factor was the popcorn-like 2-acetyl1-pyrroline. This was followed by the roasty/earthy 2-acetylthiazole (FD factor of 64), 2-furanmethanethiol with an FD factor of 32, 2-methoxyphenol with an FD factor of 32 and the seasoning-like 3-hydroxy-4,5-dimethyl-2 $(5 \mathrm{H})$-furanone with an FD factor of 32 . Others with lower FD factors were; 2-methylbutanal, 2-methylpyrazine, benzaldehyde, 4-hydroxy-2,5-dimethyl-3(2H)furanone, 2,5-dimethylpyrazine and 2-acetylpyridine. However, 2-furanmethanethiol, 4-hydroxy-2,5-dimethyl$3(2 \mathrm{H})$-furanone, 2-methoxyphenol, 2-acetyl-2-thiazoline and some saturated long chain aldehydes were detected only in fried snail and not in boiled snail. With the exception of the aforementioned compounds, the same sets of odorants identified in boiled snails were also detected in fried snails. Worthy of note is the significant presence of aroma compounds eliciting the popcorn-like note in the fried snail meat. 2-Acetyl-1-pyrroline, 2-acetylpyridine and 2-acetyl-2-thiazoline are examples of compounds with the popcorn-like note. 2-Acetyl-2-thiazoline which had the lowest FD factor (4) among the group has previously been identified as aroma component of cooked meat of spiny lobster [23] and American lobster (Homarus americanus) [24]. This aroma-active compound was shown to be thermally generated by the reaction of cysteine with ribose [25].

In addition, the presence of the coffee-like 2-furanmethanethiol and 2-acetylthiazole in the fried snail meat are of particular interest. While, majority of Sulphur compounds such as thiazoles, sulfides and thiophenes are chemically stable and can be extracted easily, thiols are very reactive and susceptible to oxidation, dimerization, and reacts with carbonyls. Hence they deserve special attention to ensure minimum losses during analysis. 2-Acetylthiazole and 2-furanmethanethiol have been reported as major odorants in coffee [26] and identified in cooked meat, popcorn and baguette bread [27]. Furthermore, 2-furanmethanethiol has been identified as a major aroma component of steamed mangrove crab (Scylla serrata) [28]. On the other hand, 2-acetylthiazole a product of non-enzymatic browning reactions between reducing sugars and amino acids in the presence of $\mathrm{H}_{2} \mathrm{~S}$ 

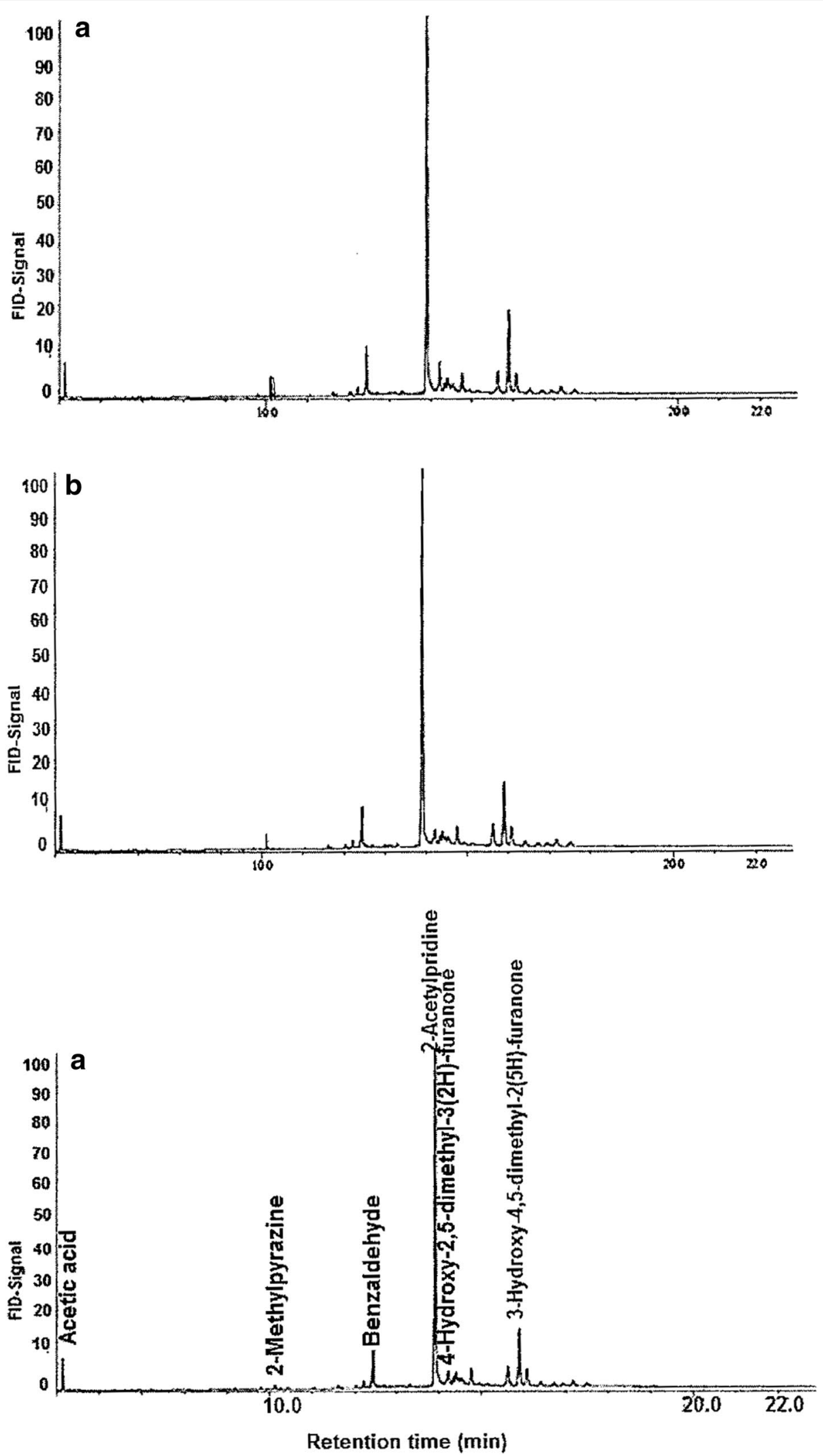

Fig. 1 Characteristic gas chromatograms of solvent extracted African giant snail meat: a raw, b boiled and $\mathbf{c}$ fried 
<smiles>CC(=O)C(C)O</smiles><smiles>CCC(C)C=O</smiles>

Acetoin<smiles>SCc1ccco1</smiles><smiles>CCCCCCCC=O</smiles><smiles>CC(=O)c1nccs1</smiles><smiles>COc1ccccc1O</smiles><smiles>CC1=C(O)C(=O)OC1C</smiles><smiles>CC(=O)c1ccccn1</smiles><smiles>Cc1cnccn1</smiles><smiles>O=Cc1ccccc1</smiles><smiles>Cc1cnc(C)cn1</smiles><smiles>C=CC(=O)CCCCC</smiles><smiles>CC1=C(O)C(=O)C(C)O1</smiles><smiles>CC(=O)/C=C1\C(C)=C(/C=C(\C)C(C)=O)CCC1(C)C</smiles>
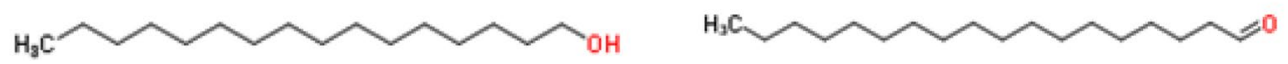

Fig. 2 Aroma-active compounds in boiled and fried African giant snail meat

[28], has been identified in nearly all cooked or roasted food aromas [28]. For instance, 2-acetylthiazole was reported as important odorant in steamed squid [21] and fried prawn meat [29].

Other thermally induced carbohydrate or protein degradation compounds such as 4-hydroxy-2,5-dimethyl-3(2H)-furanone (HDMF, furanone ${ }^{\circledR}$ ), and 3-hydroxy-4,5-dimethyl-2(5H)-furanone (sotolon) were detected with higher FD factors in the fried and boiled snail meats respectively (Tables 1,2 ). Furanone and sotolon are important aroma compounds and are considered key flavor odorants in many food products. They are also highly appreciated in the food industry. Furanone and sotolon are products of the Maillard reaction and numerous methods for their synthesis have been published [30, 31].

Additionally, the identification of $\beta$-ionone and $\beta$-isomethyl ionone for the first time in the snail meat was of interest. Although these aroma compounds exhibited low FD factors in the snail samples, they are known for their significant contribution to the aroma of flowers and foods [32]. In nature, $\beta$-ionone an example of Apo carotenoid is 


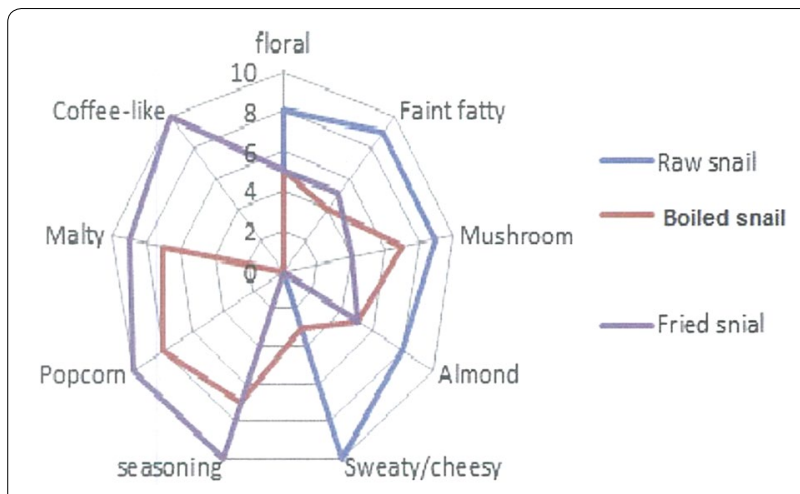

Fig. 3 Comparative aroma profiles of raw, boiled and fried snail meat

obtained by specific cleavage of $\beta$-carotenoid. This reaction is often catalyzed by the action of carotenoid cleavage deoxygenase 1 (CCD 1), which cleaves carotenoids at the 9,10 position and $9^{\prime}, 10^{\prime}$ position in the presence of oxygen [33]. However, Baldermann et al. [34] have shown that $\beta$-ionone can also be produced through carotenoid-cleavage like enzymes in Enteromorpha compressa (L.) Nees. Thus, the formation of this compound by carotenoid-cleavage like enzymes in raw snail meat seems likely.

\section{Contribution of aroma compounds to the overall aroma quality of the raw and thermally processed snail meats} Finally, to have an idea of the contribution of the odorants to the aroma characteristics of the raw and thermally processed snail meats exhibited in Fig. 3, the 13 odorants detected through AEDA as the key odorants (FD factors $\geq 8$ ) (Table 3) were quantified. Results of the aroma potencies showed that fried snail meat exhibited greater potency for 3-hydroxy-4,5-dimethyl-2(5H)-furanone (sotolon), 2-acetyl-1-pyrroline, 2-furanmethanethiol and 2-methylbutanal as revealed by their high odor activity values (OAVs) (Table 3). Again, boiled snail meat exhibited similar but lower potency for the same aroma compounds as those of the fried snail meat. Moreover, the raw snail showed stronger potencies for 1-octen-3one, $\beta$-ionone and octanal respectively. While, the OAVs indicated that 4-hydroxy-2,5-dimethyl-3(2H)-furanone (furanone), octanal, 1-octen-3-one, 2-acetylpyridine, 2-methoxyphenol and 2-methylpyrazine contributed to the seasoning, popcorn and coffee-like aroma of the

Table 2 Most aroma-active components (FD $\geq 4)$ in Fried giant snail meat ( $A$. fulica)

\begin{tabular}{|c|c|c|c|c|c|c|}
\hline No & Compound $^{a}$ & Odour note & Fraction $^{b}$ & DB-5 & FFAP & FD \\
\hline 1 & Acetoin & Buttery & NBF & nd & 1275 & 4 \\
\hline 2 & Acetic acid & Vinegar-like & $\mathrm{AF}$ & 635 & 1450 & 4 \\
\hline 3 & 2-Methylbutanal & Malty & NBF & 663 & 912 & 8 \\
\hline 4 & 2-Methylpyrazine & Popcorn-like & NBF & 820 & nd & 8 \\
\hline 5 & Butanoic acid & Sweaty, cheesy & $\mathrm{AF}$ & 835 & 1619 & 4 \\
\hline 6 & 2,5-Dimethylpyrazine & Nutty & NBF & 906 & nd & 16 \\
\hline 7 & 2-Furanmethanethiol & Coffee-like & $\mathrm{AF}$ & 907 & 1428 & 32 \\
\hline 8 & 2-Acetyl-1-pyrroline & Popcorn-like & NBF & 922 & 1371 & 256 \\
\hline 9 & Benzaldehyde & Almond-like & NBF & 963 & 1524 & 8 \\
\hline 10 & 1-Octen-3-one & Mushroom-like & NBF & 977 & 1295 & 4 \\
\hline 11 & 2-Acetylthiazole & Roasty, earthy & NBF & 1020 & 1624 & 64 \\
\hline 12 & 2-Acetylpyridine & Popcorn-like & NBF & 1031 & 1551 & 16 \\
\hline 13 & 4-Hydroxy-2,5-dimethyl-3(2H) furanone & Caramel-like & AF & 1067 & 2029 & 8 \\
\hline 14 & 2-Methoxyphenol & Smoky, sweet & NBF & 1088 & 1858 & 32 \\
\hline 15 & 2-Acetyl-2-thiazoline & Popcorn & NBF & 1091 & 1755 & 4 \\
\hline 16 & 3-Hydroxy-4,5-dimethyl-2(5H) furanone & Seasoning-like & $\mathrm{AF}$ & 1107 & 2200 & 32 \\
\hline 17 & $\beta$-Iso-methyl ionone & Floral & NBF & 1534 & nd & 4 \\
\hline 18 & Tetradecanal & Creamy, fishy & NBF & 1601 & nd & 4 \\
\hline 19 & Hexadecanal & Cardboard-like & NBF & 1800 & nd & 4 \\
\hline 20 & Octadecanal & Oily & NBF & 1818 & nd & 4 \\
\hline 21 & Hexadecanol & Waxy, floral & NBF & 1854 & nd & 4 \\
\hline 22 & Hexadecanoic acid & Waxy & AF & 1984 & nd & 4 \\
\hline
\end{tabular}

$A F$ acidic fraction, NBF neutral and basic fraction, $F D$ flavour dilution

a Compounds were identified by comparing their retention indices on DB-5 and FFAP columns, mass spectra, and their aroma impressions were compared with the respective reference compounds

b Fractions in which the odorants were detected by GC-O after fractionation 
Table 3 Concentrations ( $\mu \mathrm{g} \mathrm{Kg}^{-1}$ fresh weight) and odour activity values (OAVs) of aroma-active odorants (FD $\geq 8$ ) in raw, boiled and fried giant snail ( $A$. fulica)

\begin{tabular}{|c|c|c|c|c|c|c|c|c|c|}
\hline \multirow[t]{2}{*}{ No. } & \multirow{2}{*}{$\begin{array}{l}\text { DB- } \\
5\end{array}$} & \multirow[t]{2}{*}{ Compound } & \multirow{2}{*}{$\begin{array}{l}\text { Snail } \\
\text { Raw }\end{array}$} & \multirow{2}{*}{$\begin{array}{l}\text { Conc. } \\
\text { Boiled }\end{array}$} & \multirow{2}{*}{$\begin{array}{l}\text { Snail Conc. } \\
\text { Fried }\end{array}$} & \multirow{2}{*}{$\begin{array}{l}\text { Odour thresholds } \\
\text { in water } \mu \mathrm{g} \mathrm{Kg}^{-1}\end{array}$} & \multicolumn{3}{|c|}{ OAVs } \\
\hline & & & & & & & Raw & Boiled & Fried \\
\hline 1 & 663 & 2-Methylbutanal & nd & $16.8 \pm 1.0$ & $30.0 \pm 1.0$ & $1^{\mathrm{a}}$ & nd & 16 & 30 \\
\hline 2 & 820 & 2-Methylpyrazine & nd & $100.3 \pm 0.7$ & $126.7 \pm 0.4$ & $60^{b}$ & nd & 1.7 & 2.1 \\
\hline 3 & 906 & 2,5-Dimethylpyrazine & nd & $40.0 \pm 1.4$ & $45.1 \pm 1.5$ & $800^{b}$ & nd & $<1$ & $<1$ \\
\hline 4 & 907 & 2-Furanmethanethiol & nd & nd & $4.7 \pm 0.1$ & $0.005^{b}$ & nd & nd & 940 \\
\hline 5 & 922 & 2-Acetyl-1-pyrroline & nd & nd & $123.6 \pm 2.2$ & $0.1^{\mathrm{a}}$ & nd & nd & 1236 \\
\hline 6 & 963 & Benzaldehyde & $13.5 \pm 0.0$ & $16.4 \pm 0.1$ & $20.0 \pm 0.1$ & $350^{a}$ & $<1$ & $<1$ & $<1$ \\
\hline 7 & 977 & 1-Octen-3-one & $1.2 \pm 0.0$ & $0.9 \pm 0.0$ & $0.1 \pm 0.0$ & $0.005^{\mathrm{a}}$ & 240 & 180 & 20 \\
\hline 8 & 1006 & Octanal & $45.9 \pm 1.0$ & $63.2 \pm 1.0$ & $78.9 \pm 2.5$ & $8^{a}$ & 5.7 & 7.9 & 9.9 \\
\hline 9 & 1020 & 2-Acetylthiazole & nd & $5.7 \pm 0.1$ & $15.9 \pm 0.1$ & $10^{\mathrm{a}}$ & nd & $<1$ & 1.5 \\
\hline 10 & 1031 & 2-Acetylpyridine & nd & $70.0 \pm 2.1$ & $102 \pm 1.5$ & $19^{\mathrm{a}}$ & nd & 3.7 & 5.4 \\
\hline 11 & 1067 & $\begin{array}{l}\text { 4-Hydroxy-2,5-dimethyl-3(2H) } \\
\text { furanone }\end{array}$ & nd & nd & $46.5 \pm 1.0$ & $5^{\mathrm{a}}$ & nd & nd & 9.3 \\
\hline 12 & 1088 & 2-Methoxyphenol & nd & nd & $12.9 \pm 0.1$ & $2.5^{\mathrm{a}}$ & nd & nd & 5.2 \\
\hline 13 & 1107 & $\begin{array}{l}\text { 3-Hydroxy-4,5-dimethyl-2(5H) } \\
\text { furanone }\end{array}$ & nd & $6.1 \pm 0.1$ & $11.2 \pm 1.4$ & $0.001^{a}$ & nd & 6100 & 11,200 \\
\hline 14 & 1457 & $\beta$-lonone & $5.4 \pm 0.1$ & $0.7 \pm 0.0$ & nd & $0.03^{c}$ & 180 & 23 & nd \\
\hline 15 & 1534 & $\beta$-Iso-methyl ionone & $12.2 \pm 0.1$ & $1.1 \pm 0.0$ & $0.9 \pm 0.0$ & nd & nd & nd & nd \\
\hline
\end{tabular}

Mean \pm SD

OAVs odour activity value was calculated by dividing the concentration with the threshold value of compound in water, nd not determined

a Rychlik et al. [35]

b Tressl [36]

c Silva et al. [37]

thermally processed African giant snail meat. 1-Octen3 -one, octanal and $\beta$-ionone were the major contributors to the mushroom, sweaty/cheesy notes of the raw snail meat. A detailed analysis on aroma recombination experiments will be needed to determine the contribution of single odorant to the overall aroma of the snail meat.

\section{Sensory evaluation}

To corroborate the analytical data, sensory evaluations were performed on the snail samples by trained panelists. Sensory evaluation of the raw, boiled and fried snail meats revealed distinct aroma characteristics (Fig. 3). While the raw snail meat exhibited sweaty/cheesy, mushroom and faint-fatty notes, the boiled snail meat was characterized by popcorn, seasoning-like, malty and mushroom notes. The fried snail elicited similar but stronger aroma notes as the boiled snail meat. In addition, the fried snail meat also had strong coffee-like nuance.

\section{Conclusion}

Applications of the AEDA, GC-O and OAVs revealed significant differences in the aroma profiles of the raw and thermally processed snail meats. Whilst the aroma profile of the raw snail meat was dominated with the floral-like $\beta$-ionone and $\beta$-iso-methyl ionone, sweaty/ cheesy-like butanoic acid, and the mushroom-like 1-octen-3-one, the boiled and fried samples were dominated with the thermally generated odorants like 2-methylpyrazine, 2,5-dimethylpyrazine, 2-acetylthiazole and 2 -acetylpyridine. Among aroma-active compounds detected in the fried snail and not in the boiled snail were; 2-furanmethanethiol, 4-hydroxy-2,5-dimethyl-3(2H)furanone, 2-methoxyphenol, 2-acetyl-2-thiazoline and some saturated long chain aldehydes. In addition, results have shown that sotolon, 2-acetyl-1-pyrroline, 2-furanmethanethiol, 2-methylbutanal, 1-octen-3-one, octanal, furanone, 2-methoxyphenol, 2-acetylpyridine, 2-acetylthiazole, and 2-methylpyrazine contributed to the overall aroma of the thermally processed snail meat. Finally, a detailed analysis on aroma recombination experiments will be needed to determine the contribution of single odorant to the overall aroma of the snail meat.

\section{Materials and methods} Materials

Thirty adult giant snails (A. marginata and A. achatina) weighing between 82.10 and $96.40 \mathrm{~g}$ were collected after rainfall from three different gardens located in Port Klang, Malaysia. The shells of the snails were removed 
and the soft body was washed with distilled water and subsequently frozen $\left(-20^{\circ} \mathrm{C}\right)$.

\section{Thermal processing}

Thawed snail meats were divided into three batches of $200 \mathrm{~g}$ each. A batch was cooked in unsalted boiling water $\left(100{ }^{\circ} \mathrm{C}\right)$ [20] for $15 \mathrm{~min}$. After boiling, the snail was frozen with liquid nitrogen and ground into powder. A second batch was pan-fried at $160{ }^{\circ} \mathrm{C}$ without using fat as described earlier by Mall and Schieberle [20]. The frying protocol was carried out in an open pan heated with cooking gas as is done in domestic uses. The frying was continued for $8 \mathrm{~min}$. The snail meat was stirred and reversed every minute for uniform cooking. After frying, the snail was cooled and frozen with liquid nitrogen before milling into powder. The third batch was used as the control.

\section{Chemicals}

The following reference compounds: acetic acid, acetoin, 2-methylbutanal, 2-methylpyrazine, 2,5-dimethylpyrazine, 2-furanmethanethiol, 2-acetyl-1-pyrroline, benzaldehyde, 1-octen-3-one, octanal, linalool, 2-acetylthiazole, 2-acetylpyridine, 4-hydroxy-2,5-dimethyl-3(2H)-furanone, 2-methoxyphenol, 3-hydroxy-4,5-dimethyl-2(5H)furanone, hexadecanol, octadecanal, 2.3-pentanedione, butanoic acid, $\beta$-iso-methyl ionone, $\beta$-ionone, were from Sigma-Aldrich (St. Louis MO). Stock standard solutions $10^{3}$ or $10^{4} \mu \mathrm{g} \mathrm{mL} \mathrm{m}^{-1}$ of each compound was prepared as described earlier [21].

\section{Sample preparation}

Powdered snail meat $(100 \mathrm{~g})$ was blended with anhydrous sodium sulphate $(50 \mathrm{~g})$ and diethyl ether $(300 \mathrm{~mL})$ followed by continuous stirring $(2 \mathrm{~h})$. The obtained mixture was filtered and subjected to solvent assisted flavor evaporation (SAFE) [22]. The obtained distillate was dried over anhydrous sodium sulphate and concentrated to approximately $50 \mathrm{~mL}$ [23].

\section{Fractionation of volatiles}

The SAFE distillate was treated with $150 \mathrm{~mL}$ of aqueous sodium bicarbonate $\left(0.5 \mathrm{~mol} \mathrm{~L}^{-1}\right)$ to yield an organic and aqueous layer respectively. The organic layer was washed twice with $75 \mathrm{~mL}$ of brine and dried over anhydrous sodium sulphate to produce the neutral/basic fraction (NBF). The aqueous layers were combined and acidified ( $\mathrm{pH} 2.5)$ with $\mathrm{HCl}(16 \%)$ and extracted with diethyl ether $(200 \mathrm{~mL})$. The extract was subsequently dried over anhydrous sodium sulphate to yield the acidic fraction (AF). Both NBF and AF were concentrated to $100 \mu \mathrm{L}$ each as described by Lasekan et al. [23] the resulted fractions were subjected to $\mathrm{GC}-\mathrm{O}$ and $\mathrm{GC}-\mathrm{MS}$.

\section{Extraction of raw snail meat}

Minced raw snail (200 g) was extracted as described for the thermally processed samples above. The obtained mixture was subjected to SAFE distillation [22] and extracted with dichloromethane $(2 \times 200 \mathrm{~mL})$. The extract was dried over anhydrous sodium sulphate and the organic phase was subsequently concentrated as described above. The concentrated extract was subjected to $\mathrm{GC}-\mathrm{O}$ and $\mathrm{GC}-\mathrm{MS}$.

\section{GC-MS and GC-FID analyses}

A Shimadzu (Kyoto, Japan) QP-5050A GC-MS equipped with a GC-17 A Ver.3, a flame ionization detector (FID) and fitted differently with columns DB-FFAP and DB-5 (each, $30 \mathrm{~m} \times 0.32 \mathrm{~mm}$ i.d., film thickness $0.25 \mu \mathrm{m}$; Scientific, Inc., Ringoes, NJ) was employed [24]. The gas chromatographic and mass spectrometric conditions were the same as described previously by Lasekan and Ng [26]. The HP Chemstation Software was employed for the data acquisition and mass spectra were identified using the NIST/NB575K database.

\section{GC-O analysis}

A Trace Ultra 1300 gas chromatograph (Thermo Scientific, Waltham, MA, USA) fitted with either a DB-FFAP or DB-5 column 1:(30 $\mathrm{m} \times 0.32 \mathrm{~mm}$ i.d., film thickness, $0.25 \mu \mathrm{m}$, Scientific Instrument Services, Inc., Ringoes, NJ) and an ODP 3 olfactory Detector Port (Gerstel, Mulheim, Germany), with additional supply of humidified purge air, was operated as earlier reported by Lasekan et al. [21]. The split ratio between the sniffing port and the FID detector was 1:1. Two replicate samples were sniffed by three trained panelists who presented normalized responses, with strong agreement with one another.

\section{Identification and quantification}

The linear retention indices were calculated according to Kovats method using a mixture of normal paraffin $\mathrm{C}_{6}-\mathrm{C}_{28}$ as external references [24]. The identification of compounds was as described earlier by Lasekan [24]. Quantitative data were obtained by relating the peak area of each compound to that of the corresponding external standard and were expressed as $\mu \mathrm{g} \mathrm{kg}^{-1}$.

\section{Aroma extracts dilution analysis (AEDA)}

The extracts of snail meat were diluted step wise twofold with dichloromethane by volume to obtain dilutions of 1:2, 1:4, 1:8, 1:16 and so on [24]. Each of the obtained dilution was injected into the $\mathrm{GC}-\mathrm{O}$. The highest dilution in which an aroma compound was observed is referred to as the flavor dilution (FD) factor of that compound [25]. 


\section{Aroma profile analysis}

Snail meats (raw, boiled and fried) (40 g each) were placed inside glass container $(7 \mathrm{~cm} \times 3.5 \mathrm{~cm})$ and were orthonasally analyzed as described by Lasekan and $\mathrm{Ng}$ [26]. Reference compounds were: 3-hydroxy-4,5-dimethyl-2(5H)-furanone (seasoning), 2-acetyl-1-pyrroline (popcorn), 2-methylbutanal (malty), 2-furfurylthiol (coffee-like), benzaldehyde (almond), 1-octen-3-one (mushroom), butanoic acid (sweaty/cheesy), and linalool (floral). An unstructured scale was used to rate each descriptor by panelists. The scale was from 0 to 10 , where $0=$ not detectable, $5=$ weak, and $10=$ strong. Final results were produced as a web plot.

\section{Authors' contributions}

OL carried out the design of the study, participated in flavor analysis and drafted the manuscript. MM, ML and FD prepared the chemicals, carried out thermal processing and performed flavor analysis as well. All authors read and approved the final manuscript.

\section{Acknowledgements}

The authors are grateful for the extensive financial support received from the Ministry of higher education, Malaysia.

\section{Competing interests}

The authors declare that they have no competing interests.

\section{Availability of data and materials}

All data and materials used are already attached.

\section{Consent for publication}

All the authors have given their consent to publish this article.

\section{Ethics approval and consent to participate}

The experiment was conducted according to the rules of the Ethical committee of the University Putra Malaysia, Malaysia.

\section{Funding}

This research was funded by the Ministry of higher education, Malaysia via the fundamental research Grant No: 5524558.

\section{Publisher's Note}

Springer Nature remains neutral with regard to jurisdictional claims in published maps and institutional affiliations.

Received: 28 July 2017 Accepted: 16 April 2018

Published online: 24 April 2018

\section{References}

1. Lv S, Zhang Y, Liu HX, Hu L, Yang K, Steinmann P, Chen Z, Wang LY, Utzinger JR, Zhou XN (2009) Invasive snails and emerging infectious disease: results from the first National Survey on Angiostrongylus cantonesis in China. PLoS Negl Trop Dis 3:e368. https://doi.org/10.1371/ journalpntd.0000368

2. Wu SP, Hwang CC, Huang HM, Chang HW, Lin YS, Lee PF (2007) Land Mollusca fauna of the Dongsha Island with twenty new recorded species. Taiwania 52:145-151

3. National Agriculture Library, National Invasive Species Information Center (2016) http://www.invasivespeciesinfo.gov/. Accessed 10 Feb 2017

4. Fagbuaro O, Oso JA, Edward JB, Ogunleye RF (2006) Nutritional status of four species of giant land snails in Nigeria. J Zhejiang Univ Sci B 7:686-689
5. Apata ES, Falola AR, Sanwo SK, Adeyemi KO, Okeowo TA (2015) Physicochemical and organoleptic evaluation of African giant land snails (Achatina spp.) meat. Int J Agric Sci Nat Res 2:24-27

6. Rekha SR, Munsil M, Neelavara AA (2015) Effect of climate change on invasion risk of giant African snail (A. fulica) in India. PLoS ONE 10:e0143724. https://doi.org/10.1371/journal.pone.0143724

7. Etim LB, Aleruchi C, Obande GA (2016) Antibacterial properties of snail mucus on bacteria isolated from patients with wound infection. Br Microbiol Res J 11:1-9

8. Brieva A, Philips N, Tejedor R, Guerrero A, Pivel JP, Alonso-Lebrero J (2008) Molecular basis for the regenerative properties of a secretion of the mollusk Cryptomphalus aspersa. Skin Pharm Physiol 21:15-22

9. Kim YS, Jo YY, Chang IM, Toida T, Park Y, Linhardt RJ (1996) A new glycosaminoglycan from the giant African snail Achatina fulica. J Biol Chem 271:11750-11755

10. Dragicevic O, Baltic MZ (2005) Snail meat: significance and consumption. Veterinarski glasnik 59:463-474

11. Babalola OO, Akinsoyinu AO (2009) Proximate composition and mineral profile of snail meat from different breeds of land snail in Nigeria. Pakistan J Nutr 8:1842-1844

12. Sekiwa Y, Kubota K, Kobayashi A (1997) Characteristic flavor components in the brew of cooked clam (Meretrix lusoria) and the effect of storage on flavor formation. J Agric Food Chem 45:826-830

13. Giogios I, Kalogeropoulos N, Grigorakis K (2013) Volatile compounds of some popular Mediterranean seafood species. Med Mar Sci 14:343-352

14. Fratini G, Lois S, Pazos M, Parisi G, Medina I (2012) Volatile profile of Atlantic shell fish species by HS-SPME GC/MS. Food Res Int 48:856-865

15. Chung HY, Yung IK, Ma WCJ, Kim JS (2002) Analysis of volatile components in frozen and dried scallops (Patinopecten yessoensis) by gas chromatography/mass spectrometry. Food Res Int 35:43-53

16. Condurso C, Tripodi G, Cincotta F, Lanza CM, Mazzaglia A, Verzera A (2016) Quality assessment of Mediterranean shrimps during frozen storage. Ital J Food Sci 28:497-507

17. Li JL, Tu ZC, Sha XM, Zhang LU, Lin DR, Zeng K, Wang H, Pang JS, Tang PP (2017) Effect of frying on fatty acid profile, free amino acids and volatile compounds of grass carp (Ctenopharyngodon idellus) fillet. J Food Process Presev 41:e13088. https://doi.org/10.1111/jfpp.13088

18. Conte F, Verzera A, Dima G, Tripodi G, Ruolo A, Condurso C (2012) Quantitative assessment in salted red mullet (Mullus surmuletus L. 1758). Ital J Food Saf 1:27-33

19. Lasekan O, Otto S (2009) In vivo analysis of palm wine (Elaeis guineensis) volatile organic compounds (VOC) by proton transfer reaction-mass spectrometry. Int J Mass Spectrom 282:45-49

20. Mall V, Schieberle P (2016) Characterization of key aroma compounds in raw and thermally processed prawns and thermally processed lobsters by application of aroma extract dilution analysis. J Agric Food Chem 64:6433-6442

21. Lasekan O, Khatib A, Juhari H, Patiram P, Lasekan S (2013) Headspace solid-phase microextraction gas chromatography-mass spectrometry determination of volatile compounds in different varieties of African star apple fruit (Chrysophillum albidum). Food Chem 141:2089-2097

22. Engel W, Bahr W, Schieberle P (1999) Solvent assisted flavor evaporation-a new and versatile technique for the careful and direct isolation of aroma compounds from complex food matrices. Eur Food Res Technol 209:237-241

23. Lasekan O, Buettner A, Christlbuaer M (2007) Investigation of important Odorants of palm wine (Elaeis quineensis). Food Chem 105:15-23

24. Lasekan O (2017) Identification of the aroma compounds in Vitex doniana sweet: free and bound odorants. Chem Central J 11:19-26

25. Schieberle $P$ (1995) Recent developments in methods for analysis of flavor compounds and their precursors. In: Gaonkar A (ed) Characterization of food emerging methods. Elsevier, Amsterdam, pp 403-431

26. Lasekan O, Ng S (2015) Key volatile aroma compounds of three black velvet tamarind (Dialium) fruit species. Food Chem 168:561-565

27. Fratini G, Lois S, Pazos M, Parisi G, Medina I (2012) Volatile profile of Atlantic shell fish species by HS-SPME GC/MS. Food Res Int 48:856-865

28. Jin Y, Deng Y, Yue J, Zhao Y, Yu W, Liu Z, Huang H (2015) Significant improvement in the characterization of volatile compound profiles in squid using simultaneous distillation-extraction and GCXGC-TOFMS. CyTA J Food 13:434-444 
29. Zehentbauer G, Grosch W (1998) Crust aroma of baguettes 1. Key odorants of baguettes prepared in two different ways. J Cereal Sci 28:81-92

30. Yu HZ, Chen SS (2010) Identification of characteristic aroma-active compounds in steamed mangrove crab (Scylla serrate). Food Res Int 43:2081-2086

31. Cadwallader KR, Tan Q, Chen F, Meyers P (1995) Evaluation of the aroma of cooked spiny lobster tail meat by aroma extract dilution analysis. J Agric Food Chem 43:2432-2437

32. Lee GH, Suriyaphan O, Cadwallader KR (2001) Aroma components of cooked tail meat of American lobster (Homarus americanus). J Agric Food Chem 49:4324-4332

33. Hofmann T, Schieberle P (1998) Identification of key aroma compounds generated from cysteine and carbohydrates under roasting conditions. Zeits. fur Lebensmitteluntersuchung und Forsch. A 207:229-236
34. Buffo RA, Cardelli-Freire C (2004) Coffee flavor: an overview. Flavour Fragr J. 19:99-104

35. Rychlik M, Schieberle P, Grosch W (1998) Compilation of odor thresholds, odor qualities and retention indices of key food odorants. Deutsche Forschungsanstail für Lebensmittelchemie, Garching, Germany

36. Tressl R (1989) Formation of flavour components in roasted coffee. In: Parliament TH, McGorrin RJ, Ho CT (eds) Thermal generation of aromas. ACS, Symposium, Series 409. ACS, Washington DC, pp 285-301

37. Silva JMG, Valente LMP, Castro-Cunha M, Bacelar M, Guedes De Pinho P (2012) Impact of dietary plant protein levels on the volatile composition of Senegalese sole (Solea senegalensis Kaup, 1858) muscle. Food Chem 131:596-602

\section{Submit your manuscript to a SpringerOpen ${ }^{\circ}$ journal and benefit from:}

- Convenient online submission

- Rigorous peer review

- Open access: articles freely available online

- High visibility within the field

- Retaining the copyright to your article

Submit your next manuscript at $\boldsymbol{\nabla}$ springeropen.com 